\title{
Determination of cyclic elemental selenium compounds in sediments
}

\author{
J. FARELL ${ }^{1}$ AND D. WALLSCHLÄGER ${ }^{1 *}$
}

${ }^{1}$ Trent University, Peterborough, ON K9L 0G2, Canada

(*correspondence: dwallsch@trentu.ca)

Selenium (Se) is an aquatic contaminant of high current importance in North America. It is sometimes emitted from industrial operations into aquatic ecosystems, where it may cause adverse ecotoxicological effects on sensitive aquatic organisms. It is known that biogeochemical reductive processes lead to removal of soluble Se oxyanions from the water column into the associated sediments, but the exact chemical and physical identity of the resulting "elemental Se" products has not been studied previously.

In this study, we have used gas chromatography coupled to mass spectrometry (GC-MS) to investigate if discrete cyclic molecules containing zerovalent $\mathrm{Se}$ are found in sediments that were in contact with Se-impacted waters. A GC-MS method was developed that allows for the separation of cyclooctaselenium $\left(\mathrm{Se}_{8}\right)$ from cyclooctasulfur $\left(\mathrm{S}_{8}\right)$ and mixed cyclic Se-S compounds found in synthetic mixed Se-S melts, as well as for the mass spectrometric identification of such compounds.

The developed method was applied to three sediments collected from different Se-impacted fresh water bodies. Sediments were extracted with carbon disulfide $\left(\mathrm{CS}_{2}\right)$, and analyzed directly by GC-MS without further clean-up of the extracts. It was found that one of the studied sediments contained $\mathrm{Se}_{8}$, at a concentration of $7.1 \pm 0.7 \mathrm{mg} / \mathrm{kg}(\mathrm{dw})$, corresponding to $41 \%$ of the total Se concentration in that sediment. The other two sediments did not contain measurable concentrations of Se8 [1]. Additionally, the three studied sediments contained (combined) at least 12 cyclic mixed Se-S compounds [2]. We were able to identify one of them conclusively $\left(\mathrm{SeS}_{5}\right)$, but the remaining compounds could not be identified, due to poor chromatographic resolution and/or thermal instability of the compounds during GC analysis. Likewise, due to lack of analytical standards, quantification of the cyclic Se-S compounds was not possible.

This study shows that small cyclic molecules containing elemental Se are formed in sediments of Se-impacted waters. The environmental fate and ecotoxicological relevance of such molecules is unknown at this time, and should be investigated in future studies to determine if these findings are relevant to the assessment of ecotoxicological Se risk.

[1] Farell \& Wallschläger (2018) Talanta 190, 188-192 . [2] Farell \& Wallschläger (2019) Talanta 205, \# 120159. 